\title{
Obituary
}

Occasionally he strayed into the realms of Rhinology, and was interested in Nasal Flora, and the reaction of nasal mucus.

It might truly be said of him that he was a man with one hobby, his work, and for many years almost very moment of his spare time was devoted to the welfare of the deaf and dumb.

$\mathrm{He}$ was largely instrumental in acquiring excellent premises for the Nottingham and Notts. Institute for the Deaf, and the noble work done there, both by him and by his wife, will never be forgotten.

His appetite for work was insatiable, and this undoubtedly contributed to his sudden death, at a comparatively early age. His heart lay in aural surgery, and his enthusiasm knew no bounds. Younger men from London and the Provinces were frequent visitors to his clinic, and found in him a very real friend and helper. $\mathrm{He}$ was naturally kind and sympathetic, and full of humour, and his witty after-dinner speeches will long be remembered.

It was fitting that he should die in the midst of his medical friends, and the crowded church on the occasion of the Memorial Service was the last tribute of the public and of the medical profession to a man who was trusted, loved, and respected.

$\mathrm{He}$ is survived by his wife, who is the only daughter of Colonel F. W. Mahin, late American Consul in Nottingham, and by one daughter.

\section{H. Bell-TaWse.}

\section{HENRY BANKS-DAVIS}

In the last issue of this Journal a well-merited tribute was paid to the memory of the late Sir Charles Ballance, who was justly spoken of as the "great master" of aural surgery in this country, and for all time his name will go down to posterity amongst the most distinguished alumni of St. Thomas's Hospital. In this number we have to regret the passing of one of his most distinguished pupils, Henry John Banks-Davis, whose striking personality was familiar to British otologists and laryngologists during the first quarter of this century.

Our late confrère was one of the remaining few who was fortunate in having had a thorough grounding in general medicine and surgery before confining his practice to diseases of the ear, throat and nose, and, consequently, his mental vision of the "wood" was never obscured by the "trees".

This broad outlook on medicine can be appreciated readily by a glance at his qualifications as recorded in the Medical Directory, from which it will be seen that in 1895 he qualified M.R.C.S.(Eng.), M.B., B.Ch. and M.A.(Camb.) and was elected F.R.C.P.(Lond.) in 


\section{Obituary}

rgr2. In the early days after "qualifying", Banks-Davis was appointed "Demonstrator of Practical Surgery" in St. Thomas's Hospital and doubtless profited much by the pioneer work which Ballance was then doing on the pathology and surgery of the temporal bone and regions in its immediate vicinity. He then visited the surgical clinics in Paris, Vienna and Berlin. Later, his chief appointment was resident medical officer to the West London Hospital, and in due course he was elected Assistant Physician with charge of the Ear, Nose and Throat Department, and lecturer on those subjects in the very famous and successful " Post-Graduate Course" which that Hospital instituted.

When he joined the Sections of Otology and Laryngology (Royal Society of Medicine) it quickly became evident that only a large clinic could provide the rare and interesting cases which Banks-Davis could always bring for inspection by his fellow members, who eventually showed their appreciation of his work and personal qualities by electing him at short intervals President of each Section.

It will readily be understood why he had for many years a large private clientele, and from personal knowledge there can be little or no doubt that this was not only due to professional skill-which was taken for granted-but also on account of his transparent honesty of purpose coupled with a sympathy and interest which each patient felt was reserved for his particular case.

During his undergraduate days at Cambridge he was a " sprinter" of no mean calibre and also rowed in his College boat-a not surprising fact when we remember the fine physique which he preserved to much later days.

In view of Banks-Davis's former activities in all matters relating to the art and science of Oto-Laryngology, it may have seemed strange that, for the past ten years or so, he rarely appeared in social or professional circles where his former confrères frequently foregathered. This was explicable to those who were well aware that the attractions of the arena had been supplanted by an increasing desire for such peace and quiet as was not possible in London, and their certain acquisition in his beautiful country home in South Wales where, as a skilled angler, he could also enjoy his favourite gentle pastime.

There will be many among the seniors of our special departments of medicine who will delight to remember the bonhomie of their friend of former days, and at the same time be grateful for the many services he gave so unstintingly to his chosen branches of medicine.

Herbert Tilley. 